\title{
Addictive disorders in adolescents with insulin-dependent diabetes
}

\author{
Ben Haouala A., Ben Mohamed B., Jabeur M., Zemzem M., Bousleh S., Gaha L. \\ Research Laboratory "Vulnerability to Psychotic disorders", psychiatry, Monastir, Tunisian Republic.
}

\section{Background:}

Insulin-dependent diabetes in adolescents is a psychologically and behaviorally challenging chronic medical condition [1]. This situation could make adolescents more at risk for developing a nonsubstance and substance addictions.

\section{Objective and methodology :}

The aim of the present study was to assess addictive disorders in adolescents with insulindependent diabetes and to evaluate the influence of this behavior on diabetes and self-esteem.

It was a descriptive and comparative study. It concerned two groups: 31 adolescents' outpatients with type 1 diabetes follow-up at the pediatric department (Group1) and 31 college students without somatic or mental illnesses (Group2). We used the following scales: ADOSPA, CAST, Fagerström test, Facebook Addiction Scale, Video game Addiction Scale and Rosenberg Self-Esteem Scale.

\section{Results :}

The average age was 14.5 years for both groups. Adolescents with insulin-dependent diabetes used more substances (38.7\% vs $22.6 \%$ ) and had more addictive behaviors ( $61.3 \%$ vs $48.4 \%$ ) than those in group2. The most used psychoactive substance in both groups was tobacco. Furthermore, the most common addictive behavior in group1 was screen addiction, while in group2 it was video games addiction. The self-esteem was lower in diabetic adolescents (61\% vs $50 \%)$.

(1) JONKER, Deborah, DEACON, Elmari, VAN RENSBURG, Esme, et al. Illness perception of adolescents with wellcontrolled type 1 diabetes mellitus. Health psychology open, 2018, vol. 5, no 2, p. 2055102918799968.

(2) LEE, P., GREENFIELD, J. R., et CAMPBELL, L. V. Managing young people with Type 1 diabetes in a 'rave'new world: metabolic complications of substance abuse in Type 1 diabetes. Diabetic Medicine, 2009, vol. 26, no 4, p 328-333.

(3) GLASGOW, Allen M., TYNAN, Doug, SCHWARTZ, Richard, et al. Alcohol and drug use in teenagers with diabetes mellitus. Journal of Adolescent Health, 1991, vol. 12, no 1, p. 11-14.

(4) MORSE, Eric D. Addiction is a Chronic Medical Illness. North Carolina medical journal, 2018, vol. 79, no 3, p 163-165.
Moreover, we did not find any significant correlation between addictive disorders and diabetic disease.

\begin{tabular}{|c|r|r|}
\hline & Group1 & \multicolumn{1}{c|}{ Group2 } \\
\hline Substance use & $38.7 \%$ & $22.6 \%$ \\
\hline Addictive behaviors & $61.3 \%$ & $48.4 \%$ \\
\hline Self-esteem & $50 \%$ & $61 \%$ \\
\hline
\end{tabular}

Addiction and self-esteem in the study population

\section{Discussion :}

There is very little information available on comorbidity between addiction and somatic chronic diseases, even more rarely mentioned the association between the disorder of use with and / or without substance and insulindependent diabetes. According to the literature, the lifetime prevalence of drug use among type 1 diabetics varies between 5 and $25 \%$ in adolescents aged 12 to 20 years [2,3]. Cannabis was the most used drug. According to the American addiction center, the risk of substance abuse is often higher in people with chronic somatic disease than in the general population. Whether it is a cause or a consequence of chronic disease, it is essential to treat the abuse at the same time as the coexisting somatic pathology (4).

\section{Conclusion:}

Youth with chronic illness seem to be more a risk of addictive disorders and low self-esteem. Studies with larger samples are recommended in order to assess individual and environmental predictive factors.

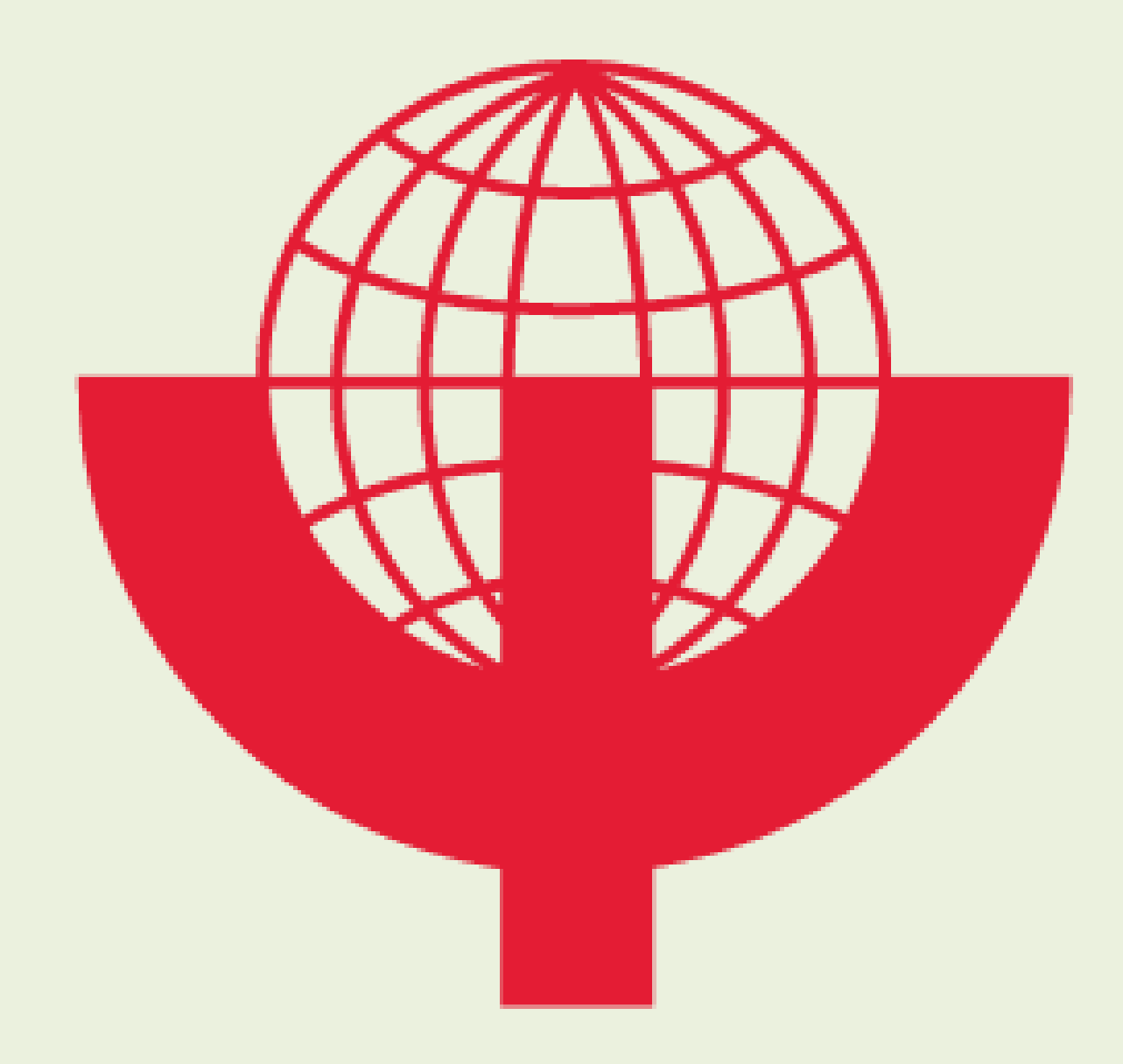

World Psychiatric Association

Lisbon2019

Declaration of interest conflicts: The authors declare no conflict of interest. 